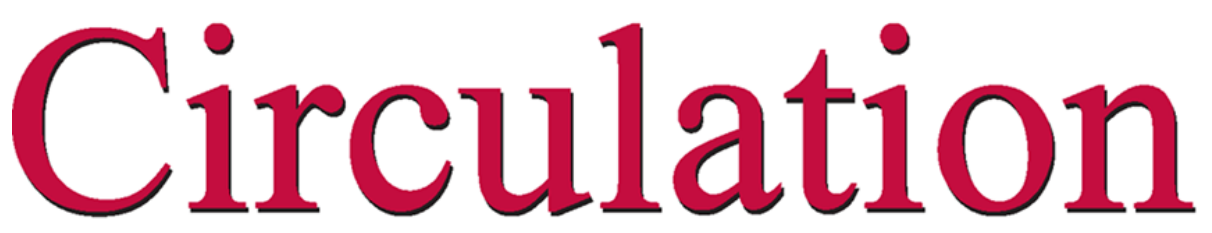

JOURNAL OF THE AMERICAN HEART ASSOCIATION
American Heart Association

Learn and Live

\title{
Percutaneous Pulmonary Valve Implantation in Humans: Results in 59
}

Consecutive Patients

Sachin Khambadkone, Louise Coats, Andrew Taylor, Younes Boudjemline, Graham Derrick, Victor Tsang, Jeffrey Cooper, Vivek Muthurangu, Sanjeet R. Hegde, Reza S. Razavi, Denis Pellerin, John Deanfield and Philipp Bonhoeffer

Circulation 2005;112;1189-1197; originally published online Aug 15, 2005;

DOI: $10.1161 /$ CIRCULATIONAHA.104.523266

Circulation is published by the American Heart Association. 7272 Greenville Avenue, Dallas, TX 72514

Copyright $@ 2005$ American Heart Association. All rights reserved. Print ISSN: 0009-7322. Online ISSN: $1524-4539$

The online version of this article, along with updated information and services, is located on the World Wide Web at:

http://circ.ahajournals.org/cgi/content/full/112/8/1189

Subscriptions: Information about subscribing to Circulation is online at

http://circ.ahajournals.org/subscriptions/

Permissions: Permissions \& Rights Desk, Lippincott Williams \& Wilkins, a division of Wolters Kluwer Health, 351 West Camden Street, Baltimore, MD 21202-2436. Phone: 410-528-4050. Fax: 410-528-8550. E-mail:

journalpermissions@1ww.com

Reprints: Information about reprints can be found online at http://www.lww.com/reprints 


\section{Percutaneous Pulmonary Valve Implantation in Humans Results in 59 Consecutive Patients}

Sachin Khambadkone, MD, MRCP*; Louise Coats, MRCP*; Andrew Taylor, MD, MRCP, FRCR*; Younes Boudjemline, MD; Graham Derrick, MRCP; Victor Tsang, MD, FRCS; Jeffrey Cooper, SCST;

Vivek Muthurangu, MRCPCH; Sanjeet R. Hegde, MRCPCH; Reza S. Razavi, MD, MRCPCH; Denis Pellerin, MD, PhD; John Deanfield, FRCP; Philipp Bonhoeffer, MD

Background - Right ventricular outflow tract (RVOT) reconstruction with valved conduits in infancy and childhood leads to reintervention for pulmonary regurgitation and stenosis in later life.

Methods and Results - Patients with pulmonary regurgitation with or without stenosis after repair of congenital heart disease had percutaneous pulmonary valve implantation (PPVI). Mortality, hemodynamic improvement, freedom from explantation, and subjective and objective changes in exercise tolerance were end points. PPVI was performed successfully in 58 patients, 32 male, with a median age of 16 years and median weight of $56 \mathrm{~kg}$. The majority had a variant of tetralogy of Fallot $(n=36)$, or transposition of the great arteries, ventricular septal defect with pulmonary stenosis $(\mathrm{n}=8)$. The right ventricular $(\mathrm{RV})$ pressure $(64.4 \pm 17.2$ to $50.4 \pm 14 \mathrm{~mm} \mathrm{Hg}, P<0.001)$, RVOT gradient ( $33 \pm 24.6$ to $19.5 \pm 15.3, P<0.001$ ), and pulmonary regurgitation (PR) (grade 2 of greater before, none greater than grade 2 after, $P<0.001)$ decreased significantly after PPVI. MRI showed significant reduction in PR fraction $(21 \pm 13 \%$ versus $3 \pm 4 \%, P<0.001)$ and in RV end-diastolic volume (EDV) $\left(94 \pm 28\right.$ versus $82 \pm 24 \mathrm{~mL} \cdot$ beat $\left.^{-1} \cdot \mathrm{m}^{-2}, P<0.001\right)$ and a significant increase in left ventricular EDV $\left(64 \pm 12\right.$ versus $71 \pm 13 \mathrm{~mL} \cdot$ beat $\left.^{-1} \cdot \mathrm{m}^{-2}, P=0.005\right)$ and effective RV stroke volume $\left(37 \pm 7\right.$ versus $42 \pm 9 \mathrm{~mL} \cdot$ beat $\left.^{-1} \cdot \mathrm{m}^{-2}, P=0.006\right)$ in 28 patients (age $19 \pm 8$ years). A further 16 subjects, on metabolic exercise testing, showed significant improvement in $\dot{\mathrm{V}}_{2} \max \left(26 \pm 7\right.$ versus $29 \pm 6 \mathrm{~mL} \cdot \mathrm{kg}^{-1} \cdot \mathrm{min}^{-1}$, $P<0.001)$. There was no mortality.

Conclusions-PPVI is feasible at low risk, with quantifiable improvement in MRI-defined ventricular parameters and pulmonary regurgitation, and results in subjective and objective improvement in exercise capacity. (Circulation. 2005; 112:1189-1197.)

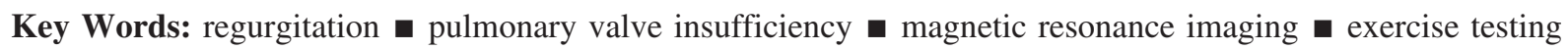
- catheterization

$\mathrm{R}$ ight ventricular outflow tract (RVOT) reconstruction forms an integral part of surgical correction in a wide spectrum of congenital heart disease. ${ }^{1-3}$ A homograft conduit has been most widely used both at primary repair and at reoperation for RVOT dysfunction. ${ }^{4-6}$ The longevity of biological valves, however, is limited because of degeneration and calcification. As a result, the need for multiple reoperations has been anticipated and observed in the adult congenital surgical series. ${ }^{7}$

Six years ago, we initiated a program to develop a valve stent that could be deployed in the RVOT by a transcatheter approach. ${ }^{8-10}$ We now report the clinical results in a series of 59 consecutive patients with immediate, early, and mediumterm results.

\begin{abstract}
Methods
The clinical program of percutaneous pulmonary valve implantation (PPVI) started at Hôpital Necker Enfants Malades (Paris, France) and continued at Great Ormond Street Hospital for Children and The Heart Hospital (London, UK). The ethics committees at these institutions approved the study protocol. Written informed consent was obtained from patients and parents as appropriate.

Patients were considered for PPVI if they had previously undergone surgery on RVOT during repair of congenital heart disease and had symptoms or RVOT dysfunction of a sufficient degree to warrant surgical intervention on the basis of conventional indications. ${ }^{11-14}$ This included right ventricular (RV) hypertension (two thirds of systemic blood pressure or greater) with outflow tract obstruction, significant pulmonary insufficiency, RV dilatation, or RV failure. Echocardiography was performed on VIVID 7 (GE, Medical Systems, Milwaukee, Wis.) in all patients. RV pressure was estimated from the tricuspid regurgitation jet and compared with cuff
\end{abstract}

Received November 23, 2004; revision received May 8, 2005; accepted May 10, 2005.

From Great Ormond Street Hospital (S.K., L.C., A.T., Y.B., G.D., V.T., J.C., J.D., P.B.); London Cardiac MR Research Group, Division of Imaging Sciences, Kings College and Guy's Hospital (V.M., S.R.H., R.S.R.); and Heart Hospital (D.P.), London, UK.

*The first 3 authors contributed equally to this work.

Correspondence to Dr Sachin Khambadkone, Consultant Cardiologist, Great Ormond Street Hospital, London WC1N 3JH, UK. E-mail khambs@gosh.nhs.uk

(C) 2005 American Heart Association, Inc.

Circulation is available at http://www.circulationaha.org 

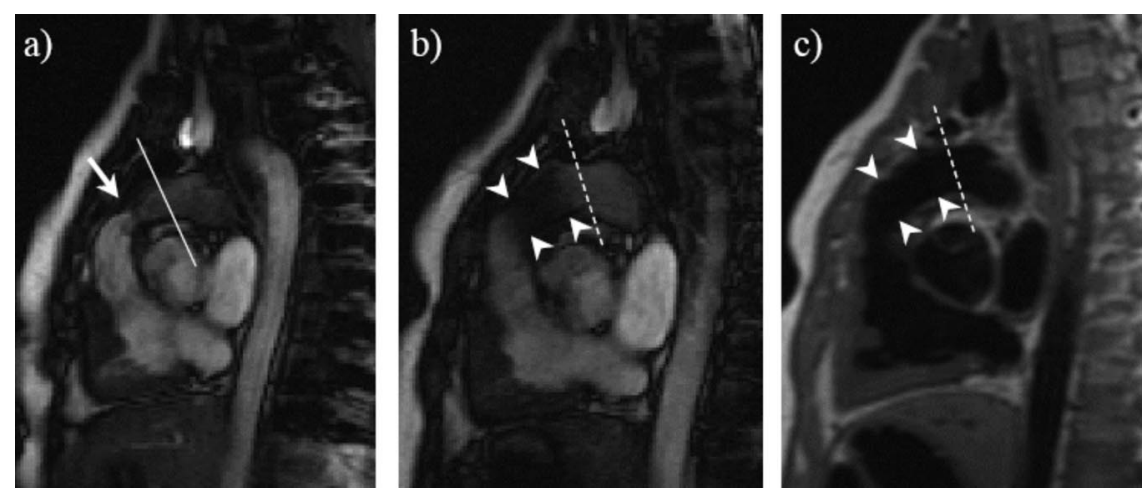

Figure 1. a, RVOT balanced SSFP images before valve stent. Pulmonary conduit narrowing (arrow). Solid white line shows imaging plane for pulmonary blood flow quantifi cation. b, RVOT balanced SSFP image after valve stent. Signal artifact from metallic component of the PPVI (arrowheads). c, RVOT "blackblood" turbo spin echo showing widely patent stent. In b and c, dotted white line shows imaging plane for pulmonary blood flow quantification. blood pressure. The RVOT gradient was calculated from the velocity across the RVOT. Color flow mapping of the RVOT and branch pulmonary arteries was used to grade the pulmonary regurgitation. This was graded into 5 categories: 0 , absent; 1 , trivial; 2 , mild; 3, moderate; and 4, severe or free pulmonary regurgitation. Any regurgitation more than grade 2 was defined as significant for the purpose of this study. ${ }^{15}$

On the basis of RVOT gradient during cardiac catheterization, we characterized patients into 2 subgroups: gradient of $\geq 30 \mathrm{~mm} \mathrm{Hg}$ (Stenosis group) and gradient $<30 \mathrm{~mm} \mathrm{Hg}$ (Regurgitation group).

We excluded patients $<5$ years of age or weighing $<20 \mathrm{~kg}$. Other exclusion criteria were pregnancy, occluded central veins, active infection, and outflow tracts with "unfavorable" morphology (narrowest RVOT diameter $>22 \mathrm{~mm}$ on angiography and conduits $<16 \mathrm{~mm}$ in diameter at surgical insertion, as described in the operation notes).

After a detailed history and physical examination, patients were assigned to a New York Heart Association (NYHA) functional class.

The design of the valved stent and technique of delivery have been reported previously. ${ }^{8}$ Under general anesthesia, vascular access was achieved through the femoral $(n=57)$ or right internal jugular $(n=2)$ route. Standard right heart catheterization with invasive systemic arterial pressure monitoring was undertaken for hemodynamic assessment. Angiography was used to determine anatomy of the RVOT and branch pulmonary arteries so as to determine feasibility, select appropriate site of deployment, and aid the choice of delivery system. Orthogonal projections were used, wherever appropriate, to obtain the dimensions of the RVOT, and projections were selected depending on RVOT morphology. Multitrack catheters with platinum image bands (placed $10 \mathrm{~mm}$ apart) were used for angiography and calibration of measurements. Hemodynamic measurements and angiography were repeated after valve implantation. After the procedure, echocardiography was performed within 24 hours to assess hemodynamics and evaluate pulmonary regurgitation. Chest radiography was performed in the frontal and lateral projections to look for stent fractures.

\section{Magnetic Resonance Imaging}

MRI was performed at $1.5 \mathrm{~T}$ with $2 \mathrm{MR}$ scanners (Symphony; Siemens Medical Systems, Erlangen, Germany; and Intera; Philips Medical Systems, Best, the Netherlands).

\section{Assessment of Ventricular Volumes and Function by Use of Cine MRI}

Retrospective gated steady-state free precession (SSFP) cine MR images of the heart were acquired in the vertical long-axis, 4-chamber view and the short-axis view covering the entirety of both ventricles ( 9 to 12 slices). ${ }^{16}$ Cine imaging of the RVOT in 2 long-axis planes was also performed for subsequent positioning of through-plane pulmonary flow quantification (Figure 1). ${ }^{16}$ Images were acquired during a single breath-hold. The cine SSFP sequence parameters were as follows: TR, 3.4 to $3.8 \mathrm{~ms}$; TE, 1.7 to $1.9 \mathrm{~ms}$; flip angle, 60 to $65^{\circ}$; slice thickness, 5 to $8 \mathrm{~mm}$; matrix, $192 \times 256$; field of view, 300 to $380 \mathrm{~mm}$; and temporal resolution, 25 to 40 phases.

\section{MR Flow Quantification}

Pulmonary artery (PA) flow data were acquired by use of a flow-sensitive gradient-echo sequence (TR, $9 \mathrm{~ms}$; TE, $5 \mathrm{~ms}$; flip angle, $15^{\circ}$; slice thickness, 5 to $7 \mathrm{~mm}$; and matrix, 128 to $192 \times 256$ ) during free breathing. A phase correction filter was used to correct for phase errors introduced by eddy currents and Maxwell terms. Image planes were located at the midpoint of the main PA/conduit before PPVI and just above the stent after PPVI to avoid any stent artifact (Figure 1). Through-plane flow data (40 phases per cardiac cycle) were acquired by use of retrospective cardiac gating. The velocity-encode peak velocity was varied according to degree of main PA/conduit stenosis.

Assessment of left ventricular (LV) and RV volumes was performed by manual segmentation of short-axis cine images with endocardial outline at end diastole and end systole (Argus; Siemens Medical Systems, Erlangen, Germany; or Easy Vision; Philips Medical Systems, Best, the Netherlands). End-diastolic and end-systolic volumes were calculated by use of Simpson's rule for each ventricle, and from these volumes, stroke volume (SV) and ejection fraction $(\mathrm{EF})$ were calculated. Where pulmonary regurgitation was present, an effective RVSV was calculated to reflect the net forward blood flow into the pulmonary arteries as follows: effective $\mathrm{RVSV}=\mathrm{RVSV}-$ pulmonary regurgitation volume.

Pulmonary blood flow was calculated from phase contrast images by use of a semiautomatic vessel edge-detection algorithm (Argus; Siemens Medical Systems, Erlangen, Germany; or Flow; Medis, the Netherlands) with operator correction. Pulmonary regurgitant (PR) fraction was calculated as percent backward flow over forward flow.

All volume and flow measurements were indexed for body surface area and expressed in $\mathrm{mL} \cdot$ beat $^{-1} \cdot \mathrm{m}^{-2}$.

\section{Objective Assessment of Exercise Capacity: Metabolic Exercise Testing}

Cardiopulmonary exercise testing was performed on a mechanically braked bicycle ergometer (Ergoline 900) with respiratory gas exchange analysis (Medgraphics, St Paul, Minn), on the same day as the pre- and post-PPVI MR studies. A ramp protocol comprising an initial period of loadless cycling to permit equilibration was used. A period of active recovery (slow cycling) was commenced after maximal exertion. Heart rate, blood pressure, and oxygen saturation were monitored in all subjects for the duration of the test.

Peak oxygen uptake $\left(\dot{\mathrm{V}}_{2} \max \right)$ and anaerobic threshold were derived from respiratory gas analysis during maximal exercise testing. Anaerobic threshold was determined by use of the modified V-slope method. Peak heart rate, blood pressure, and workload (watts) achieved were recorded.

\section{Statistical Analysis}

Descriptive data are presented as medians with interquartile range and mean \pm SD. Student's paired $t$ test was used to evaluate the difference after intervention, and a 2-tailed probability value of $P<0.05$ was considered significant. Categorical variables were compared by use of the $\chi^{2}$ test, the Wilcoxon signed-rank test, and the Mann-Whitney $U$ test. Survival curves for freedom from surgical 
TABLE 1. Patient Demographics and Diagnosis

\begin{tabular}{lc}
\hline Patient characteristics & \\
Age, $y$ (median) (range) & $16(9-43)$ \\
Weight, $\mathrm{kg}$ & $56(25-110)$ \\
Diagnosis & \\
Tetralogy of Fallot variants & 36 \\
TGA, VSD, PS & 9 \\
Ross operation & 6 \\
Truncus arteriosus & 4 \\
Other & 4 \\
RVOT characteristics & \\
Homograft & $46(78 \%)$ \\
Hancock & $5(8 \%)$ \\
Transannular patch & $3(5 \%)$ \\
Other & $5(8 \%)$ \\
\hline
\end{tabular}

TGA indicates transposition of great arteries; VSD, ventricular septal defect; and PS, pulmonary stenosis.

explantation for valve failure were obtained by use of Kaplan-Meier plots. Statistical analysis was performed on SPSS 11.0. and 12.0 (SPSS Inc., Chicago, Ill).

\section{Results}

Between January 2000 and September 2004, we attempted PPVI in 59 patients ( 32 male), with successful implantation in 58. One patient, in whom we failed to maneuver the valvestent assembly into the outflow tract, is awaiting a further attempt.

\section{Demographics and Patient Characteristics}

The median age was 16 years (range, 9 to 43 years) and median weight $56 \mathrm{~kg}$ ( 25 to $110 \mathrm{~kg}$ ); 36 patients $(61 \%)$ had variants of tetralogy of Fallot, the majority of them with pulmonary atresia $(n=18), 3$ with absent pulmonary valve syndrome, and the rest with severe pulmonary stenosis. Most patients had a homograft conduit after surgery on the RVOT $(46 / 59,78 \%)$. Only 3 patients had a "native" RVOT that had been augmented with a pericardial or homograft patch (Table 1).

\section{Immediate Hemodynamic Results}

After valve implantation, the RV systolic pressure (64.4 \pm 17.2 to $50.4 \pm 14 \mathrm{~mm} \mathrm{Hg}, P<0.001)$ and outflow gradient ( $33 \pm 24.6$ to $19.5 \pm 15.3, P<0.001$ ) (Figure 2) fell significantly. PA diastolic pressure $(9.9 \pm 3.7$ to $13.5 \pm 5.3 \mathrm{~mm} \mathrm{Hg}, P<0.001)$ increased. Angiography showed significant improvement in regurgitation, with no patient having more mild regurgitation after the procedure (Figure 3).

In the Stenosis group, there was a significant drop in RV systolic pressure $(71 \pm 15.3$ to $52.3 \pm 14.5 \mathrm{~mm} \mathrm{Hg}, P<0.001)$ and RVOT gradient $(44.6 \pm 24.3$ to $24.4 \pm 15.2 \mathrm{~mm} \mathrm{Hg}$, $P<0.001$ ). Furthermore, there was a significant drop in RV end-diastolic pressure $(11.7 \pm 3.4$ to $10 \pm 3.9 \mathrm{~mm} \mathrm{Hg}$, $P=0.018$ ).

In the Regurgitation group, however, there was no change in these parameters immediately after valve implantation (RV systolic pressure, $49.4 \pm 10.5$ to $47.2 \pm 14.1 \mathrm{~mm} \mathrm{Hg}, P=0.45$; RVOT gradient, $14.5 \pm 9.3$ to $11.8 \pm 12.1 \mathrm{~mm} \mathrm{Hg}, P=0.26$;

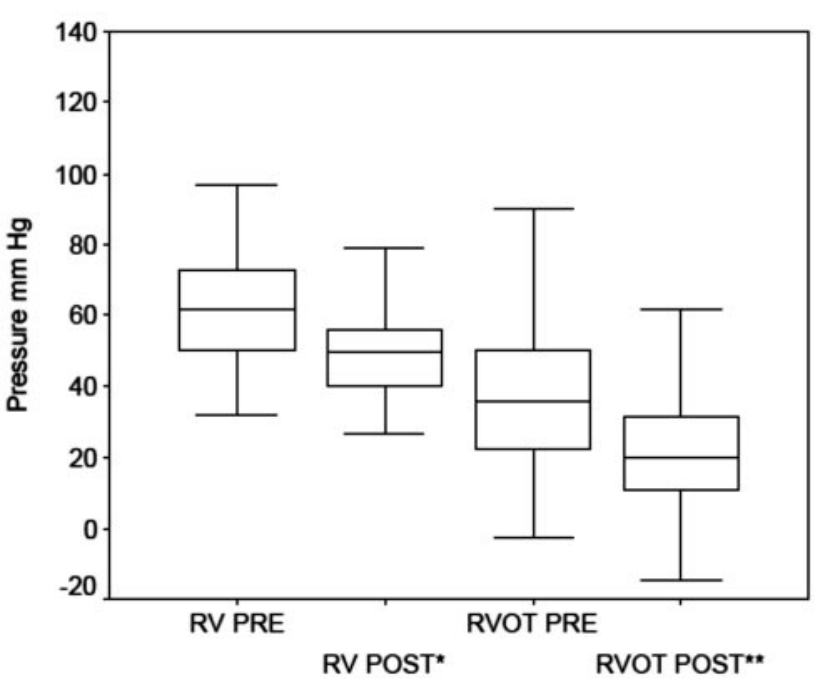

Figure 2. Hemodynamic parameters before and after pulmonary valve implantation. Pre- indicates before implantation; Post, after implantation; RVOT, RVOT gradient.

$\mathrm{RV}$ end-diastolic pressure, $10.7 \pm 2.8$ to $11.4 \pm 4.6 \mathrm{~mm} \mathrm{Hg}$, $P=0.43)$. There was, however, a significant increase in PA diastolic pressure $(10.1 \pm 3.6$ to $15.4 \pm 7.6 \mathrm{~mm} \mathrm{Hg}, P=0.001)$.

The median procedure time was 102 minutes (interquartile range, 67 to 124 minutes), and median fluoroscopy time was 21 minutes (range, 11 to 36 minutes). Five additional procedures were performed with PPVI (stenting of distal pulmonary arteries in 2 , ventricular septal defect closure in 1 , atrial septal defect closure in 1 , and occlusion of paraprosthetic leak through a mechanical aortic valve in 1).

\section{Echocardiography}

Echocardiography performed 24 hours after PPVI showed a reduction in RV pressure as estimated from TR velocity (64 \pm 1.4 to $51.8 \pm 1.9 \mathrm{~mm} \mathrm{Hg}, P<0.001)$ and RVOT gradient (63.4 \pm 23.4 to $40.5 \pm 18.2 \mathrm{~mm} \mathrm{Hg}, P<0.001$ ). There was significant reduction in grade of $\mathrm{PR}$, with all patients having grade 2 or greater PR before, and none with more than grade 2 PR after the procedure $(P<0.001)$.

\section{Magnetic Resonance Imaging}

Cardiovascular MRI was performed in 28 patients (age, $18.8 \pm 7.9$ years; range, 9.2 to 41.6 years) a median of 6 days

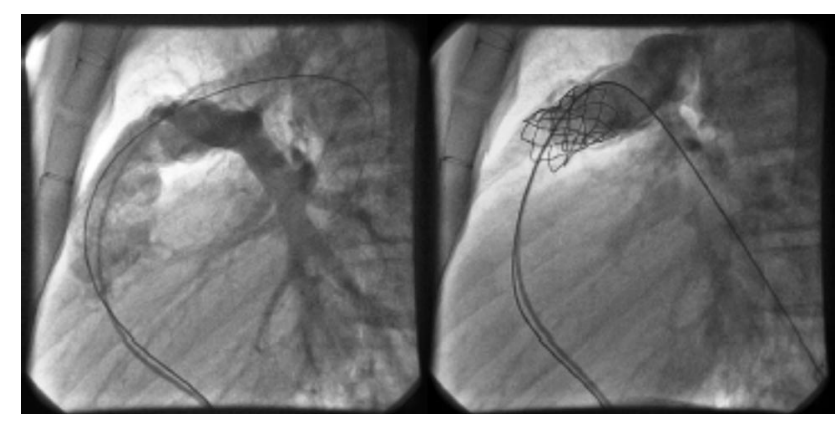

Figure 3. Lateral still-frame angiograms. Abolition of stenosis and regurgitation after pulmonary valve implantation. 
TABLE 2. MRI in Patients With PPVI

\begin{tabular}{|c|c|c|c|c|c|c|c|c|}
\hline Patient & Age, y & $\mathrm{BSA}, \mathrm{m}^{2}$ & Primary Diagnosis & $\begin{array}{l}\text { Time From } \\
\text { Before MRI } \\
\text { to PPVI, d }\end{array}$ & $\begin{array}{l}\text { Time From } \\
\text { PPVI to } \\
\text { After MRI, d }\end{array}$ & $\begin{array}{l}\text { Pulmonary RF } \\
\text { Before PPVI, \% }\end{array}$ & $\begin{array}{l}\text { Peak Systolic } \\
\text { Gradient Before } \\
\text { PPVI, mm Hg }\end{array}$ & $\begin{array}{c}\text { Metabolic } \\
\text { Exercise } \\
\text { Test Performed }\end{array}$ \\
\hline 1 & 15.2 & 1.6 & ToF, pulm. atresia & 0 & 3 & 20 & 67 & \\
\hline 2 & 12.5 & 1.3 & TGA, ASO & 11 & 8 & 20 & 60 & \\
\hline 3 & 18.8 & 1.6 & ToF, pulm. atresia & 4 & 1 & 38 & 27 & \\
\hline 4 & 14.4 & 1.6 & AoV disease (Ross) & 4 & 2 & 10 & $\ldots$ & \\
\hline 5 & 12.0 & 1.1 & AoV disease (Ross) & 4 & 1 & 28 & 58 & \\
\hline 6 & 11.7 & 1.2 & TGA, ASO & 4 & 1 & 22 & 44 & \\
\hline 7 & 25.7 & 1.6 & ToF, pulm. stenosis & 4 & 3 & 32 & 14 & \\
\hline 8 & 16.2 & 2.0 & ToF, pulm. atresia & 5 & 2 & 38 & 6 & \\
\hline 9 & 20.4 & 1.9 & TGA, ASO & 7 & 7 & 15 & 70 & \\
\hline 10 & 20.4 & 1.8 & ToF, pulm. atresia & 41 & 15 & 36 & 36 & \\
\hline 11 & 14.2 & 1.3 & ToF, pulm. stenosis & 404 & 17 & 40 & 2 & \\
\hline 12 & 13.4 & 1.6 & Sub-pulm. stenosis & 4 & 3 & 27 & 32 & \\
\hline 13 & 28.6 & 1.5 & ToF, pulm. atresia & 188 & 8 & 20 & 51 & $\sqrt{ }$ \\
\hline 14 & 41.6 & 1.7 & ToF, pulm. atresia & 176 & 64 & 15 & 24 & $\checkmark$ \\
\hline 15 & 19.9 & 2.1 & AoV disease (Ross) & 97 & 8 & 33 & 36 & $\checkmark$ \\
\hline 16 & 14.7 & 1.8 & ToF, pulm. stenosis & 4 & 3 & 6 & 34 & $\sqrt{ }$ \\
\hline 17 & 14.8 & 2.0 & ToF, pulm. stenosis & 4 & 3 & 27 & 32 & $\checkmark$ \\
\hline 18 & 15.7 & 1.6 & TGA, ASO & 225 & 2 & 10 & 71 & $\sqrt{ }$ \\
\hline 19 & 38.4 & 2.0 & AoV disease (Ross) & 132 & 50 & 0 & 33 & $\checkmark$ \\
\hline 20 & 10.7 & 1.0 & TGA, ASO & 1 & 6 & 22 & 44 & $\checkmark$ \\
\hline 21 & 10.4 & 1.1 & Common arterial trunk & 1 & 6 & 28 & 23 & $\checkmark$ \\
\hline 22 & 22.0 & 1.7 & ToF, pulm. atresia & 286 & 15 & 10 & 52 & $\sqrt{ }$ \\
\hline 23 & 24.0 & 2.2 & ToF, pulm. atresia & 1 & 1 & 24 & 51 & $\checkmark$ \\
\hline 24 & 12.5 & 1.2 & Common arterial trunk & 104 & 14 & 45 & 26 & $\checkmark$ \\
\hline 25 & 20.2 & 1.6 & ToF, pulm. atresia & 97 & 22 & 2 & 41 & $\checkmark$ \\
\hline 26 & 26.9 & 1.7 & ToF, pulm. stenosis & 50 & 55 & 4 & 34 & $\checkmark$ \\
\hline 27 & 20.3 & 2.1 & AoV disease (Ross) & 118 & 22 & 0 & 46 & $\checkmark$ \\
\hline 28 & 9.2 & 1.2 & Common arterial trunk & 2 & 2 & 5 & 59 & $\checkmark$ \\
\hline
\end{tabular}

BSA indicates body surface area; ToF, tetralogy of Fallot; pulm., pulmonary; TGA, transposition of the great arteries; ASO, arterial switch operation; and AoV, aortic valve.

before PPVI (range, 0 to 404 days) and a median of 6 days after the procedure (range, 1 to 64 days) (Table 2).

Sixty-one percent of the subjects (17/28) had a PR fraction of $\geq 20 \%$ (moderate or severe pulmonary regurgitation).

There was significant reduction in the PR fraction ( $21 \pm 13 \%$ to $3 \pm 4 \%, P<0.001)$ and $\mathrm{RV}$ end-diastolic volume (EDV) $\left(94 \pm 28\right.$ to $82 \pm 24 \mathrm{~mL} \cdot$ beat $\left.^{-1} \cdot \mathrm{m}^{-2}, P<0.001\right)$ and a significant increase in RV effective SV $(37 \pm 7$ to $42 \pm 9 \mathrm{~mL}$. beat $\left.^{-1} \cdot \mathrm{m}^{-2}, P=0.006\right)$ after PPVI. RVEF did not change (53 $\pm 14 \%$ to $55 \pm 13 \%)(P=0.36)$ (Figure 4$)$. In $46 \%$ of subjects (13/28), no PR was seen after PPVI.

There was a significant increase in LVEDV (64 \pm 12 to $71 \pm 13 \mathrm{~mL} \cdot$ beat $\left.^{-1} \cdot \mathrm{m}^{-2}, P=0.005\right)$ and LVSV ( $38 \pm 7$ to $42 \pm 9 \mathrm{~mL} \cdot$ beat $\left.^{-1} \cdot \mathrm{m}^{-2}, P=0.005\right)$. There was no significant change in the LVEF ( $63 \pm 10$ to $64 \pm 9, P=0.45$ ).

MRI was not possible in the entire cohort because of patients being referred from overseas; the presence of pacemakers, defibrillators, or stents preventing optimal imaging, or poor patient cooperation for breath-holding.

\section{Exercise Capacity}

NYHA functional class improved after PPVI (median NYHA class, from 2 to $1, P<0.001$ ) (Figure 5a). A subset of 16 consecutive patients, on cardiopulmonary exercise testing, had significant improvement in $\dot{\mathrm{V}}_{2} \max (26 \pm 7$ to $29 \pm 6 \mathrm{~mL}$ $\cdot \mathrm{kg}^{-1} \cdot \min ^{-1}, P=0.006$ ) (Figure $5 \mathrm{~b}$ ) and anaerobic threshold (14 \pm 4 to $16 \pm 3 \mathrm{~mL} \cdot \mathrm{kg}^{-1} \cdot \mathrm{min}^{-1}, P=0.008$ ) (Figure $5 \mathrm{c}$ ).

\section{Predictors of Improvement in Exercise Capacity}

The patients with improvement in their cardiopulmonary exercise had a significant reduction in PR fraction $(17 \pm 13 \%$ to $3 \pm 3 \%, P<0.001)$ and RVEDV $\left(95 \pm 25\right.$ to $84 \pm 23 \mathrm{~mL} \cdot$ beat $^{-1}$ $\left.\cdot \mathrm{m}^{-2}, P<0.001\right)$ and a significant increase in LVEDV $(65 \pm 11$ to $74 \pm 14 \mathrm{~mL} \cdot$ beat $\left.^{-1} \cdot \mathrm{m}^{-2}, P=0.003\right)$ and effective RVSV ( $38 \pm 6$ to $43 \pm 9 \mathrm{~mL} \cdot$ beat $^{-1} \cdot \mathrm{m}^{-2}, P=0.048$ ) (Table 3).

In 12 subjects, reduction in RVEDV was associated with improved $\mathrm{V}_{2}$ max (Figure 6, a and b). In 2 subjects, RVEDV increased with worsening $\dot{\mathrm{V}}_{2}$ max. Both these subjects had predominantly stenotic lesions before PPVI (PR fraction $=1 \%$ 

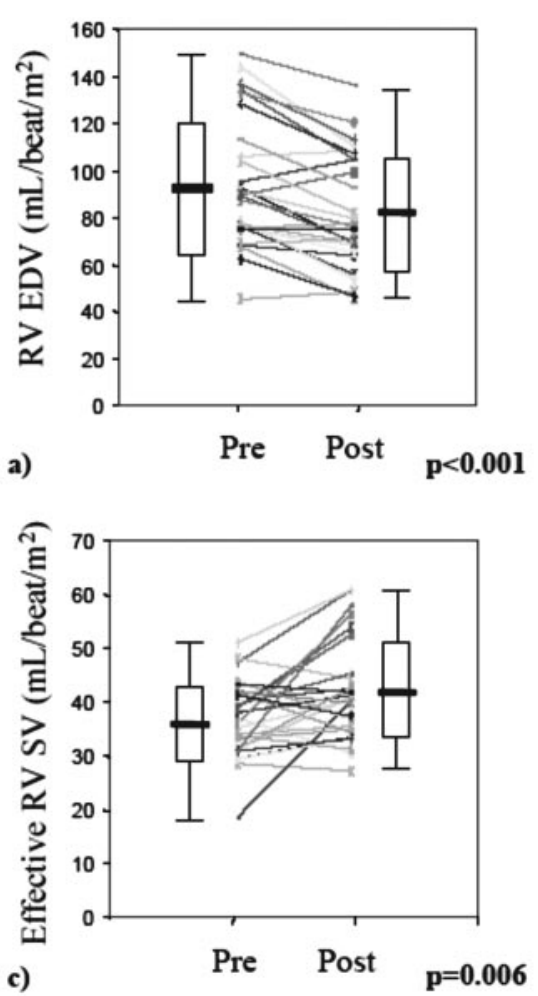

c)

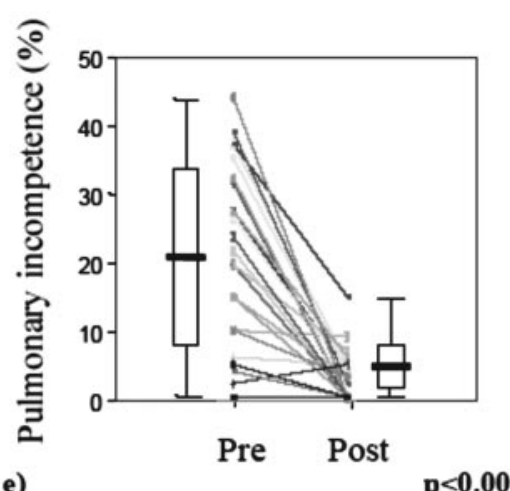

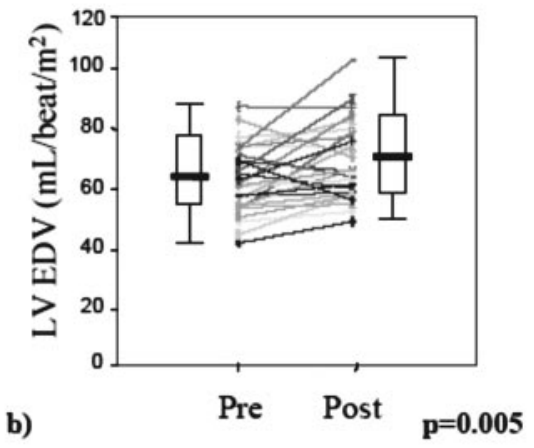

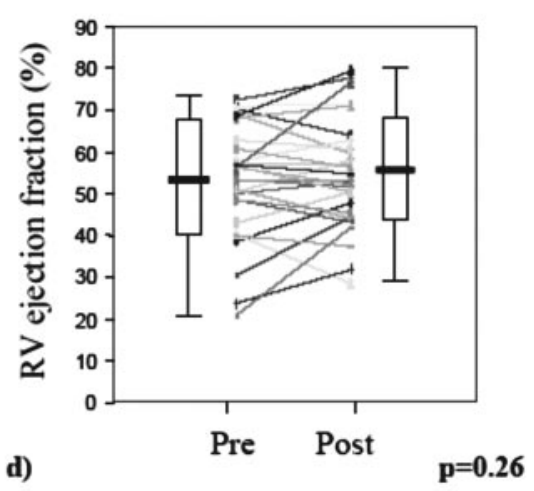

Figure 4. Plots (mean, bold line; box, $\pm S D$; upper and lower limits, maximum and minimum, respectively). a, RVEDV; b, LVEDV; c, effective RVSV; d, RVEF; and e, PR fraction before and after PPVI. and $12 \%$ before PPVI, respectively) and no significant increase in pulmonary regurgitation after PPVI (both $<12 \%$ ). In 2 other subjects, there was reduction in RVEDV but worsening of $\dot{\mathrm{V}}_{2}$ max after PPVI. Both had predominant pulmonary regurgitation (PR fraction 22\%) that decreased significantly (12\% and 6\%) after PPVI, but they had residual pulmonary stenosis.

Exercise testing could not be preformed in some patients because of poor co-operation or failure to achieve a maximal effort.

\section{Follow-Up}

The mean follow-up was $9.8 \pm 1.4$ months and $100 \%$ complete for mortality and freedom from explantation. There was no mortality during the procedure or until the last follow-up.

Serial echocardiography showed that an early decrease in RVOT gradient was sustained at the latest follow-up (mean, 9.8 months $)(63.4 \pm 23.4$ to $48.8 \pm 24.2, P=0.006)$, despite some increase compared with that immediately after the procedure $(40.5 \pm 18.2$ to $48.8 \pm 24.2, P=0.06)$. The improve- ment in regurgitation was also sustained, with only 1 patient having moderate regurgitation because of endocarditis of the valve.

\section{Procedural Complications}

There were 3 significant early complications. In 2 patients, the stent dislodged over the guide wire, and both had successful surgical homograft implantation.

There was 1 life-threatening bleeding episode in a patient with a 16-mm homograft implanted during neonatal repair of truncus arteriosus. The stenotic and calcified homograft was predilated with a 16-mm balloon, which led to dissection of the homograft. We immediately proceeded to PPVI, with successful relief of obstruction. However, the patient developed hypotension and right hemothorax, requiring emergency right pleural drainage and autotransfusion to achieve hemodynamic stability. Surgical exploration was undertaken as an emergency procedure on femoral bypass, and sutures were placed on the homograft, with successful control of bleeding. An epicardial echocardiogram showed a well-functioning 


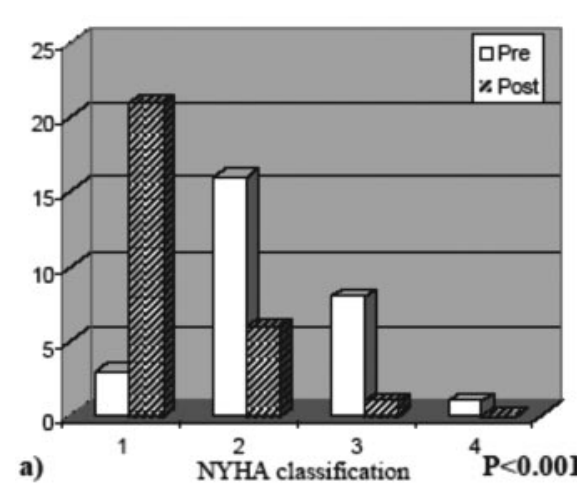

a)

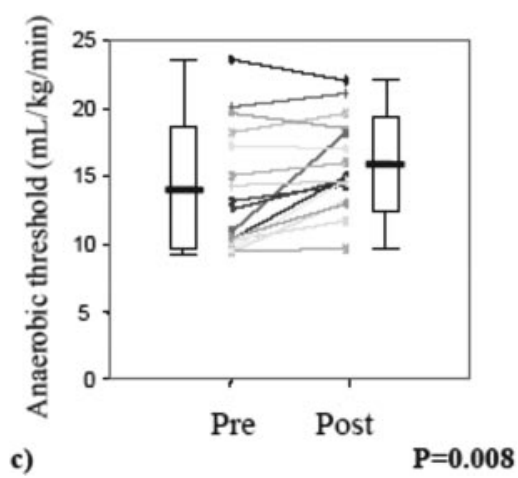

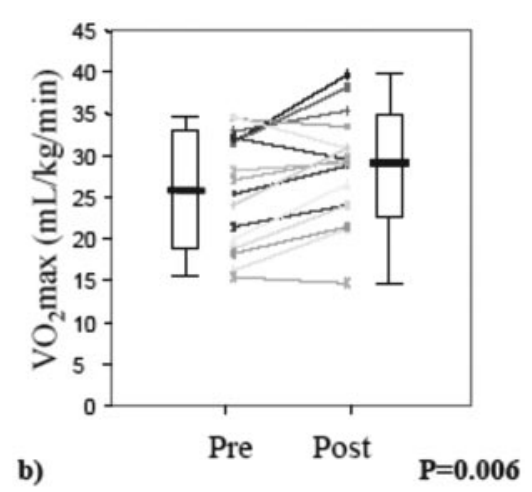

b)
Figure 5. a, NYHA classification before and after PPVI. Maximal oxygen consumption $\left(\dot{\mathrm{V}}_{2} \max \right)(\mathrm{b})$ and anaerobic threshold (c) before and after PPVI. valve-stent implant, which was left in situ, with good hemodynamics.

There were 7 minor complications, which included minor dissection of the homograft $(n=1)$ (treated conservatively); detachment of the distal tip of delivery system $(n=2)$ into the branch PA, which was snared successfully and retrieved; and local bleeding $(n=4)$, which was controlled without transfusion.

\section{Device-Related Adverse Events}

During the follow-up, there were device-related problems in 14 patients. In 7, in-stent stenosis was observed because of the "hammock effect" (Figure 7), in which the valve did not appose to the stent. Before recognition of this phenomenon, the device was explanted surgically in 3 patients. In explanted valves, there was no endothelial proliferation within the lumen or blood outside the venous wall. We believe that this was because of failure to suture the valve to the entire length of stent in the initial design of the device. There was probably a dynamic component to this mechanism that was seen better during angiography and may well be accentuated by a "Venturi" effect.

Subsequently, in 3 patients, a second stent was implanted within the first. One patient had relief of obstruction with just balloon dilatation of the "hammock" valve and is under close follow-up to watch for recurrence. The hammock effect was not observed after a change in the device design, when the whole length of the venous wall was sutured along the length of the stent.

Stent fracture was observed in 7 patients at a median of 9 months after PPVI. During meticulous follow-up, clinical problems were observed in 2. In 1 patient, the RVOT gradient increased, and the patient was successfully treated with a second valve implantation.

In the other, there was stent embolization to the right PA 9 months after the procedure. The patient presented with acute symptoms of chest pain and dyspnea. A chest radiograph revealed stent embolism to the right PA. An emergency cardiac catheterization was performed, and the stent was snared to be retrieved into the RVOT for surgical access to

TABLE 3. Metabolic Exercise Test and Ventricular Parameters on MRI in 16 Patients After PPVI

\begin{tabular}{lllr}
\hline & \multicolumn{1}{c}{ Before } & \multicolumn{1}{c}{ After } & Before vs After \\
\hline$\dot{\mathrm{V}}_{2} \mathrm{max}, \mathrm{mL} \cdot \mathrm{kg}^{-1} \cdot \mathrm{min}^{-1}$ & $26 \pm 7(16-35)$ & $29 \pm 6(15-40)$ & 0.006 \\
Anaerobic threshold, $\mathrm{mL} \cdot \mathrm{kg}^{-1} \cdot \mathrm{min}^{-1}$ & $14 \pm 4(10-24)$ & $16 \pm 3(10-22)$ & 0.008 \\
$\mathrm{RV} \mathrm{EDV}, \mathrm{mL} \cdot$ beat $^{-1} \cdot \mathrm{m}^{-2}$ & $95 \pm 25(68-150)$ & $84 \pm 23(46-136)$ & $<0.001$ \\
$\mathrm{LV} \mathrm{EDV}, \mathrm{mL} \cdot$ beat $^{-1} \cdot \mathrm{m}^{-2}$ & $65 \pm 11(46-85)$ & $74 \pm 14(55-105)$ & 0.003 \\
Corrected RV SV, $\mathrm{mL} /$ beat $^{-1} \mathrm{~m}^{-2}$ & $38 \pm 6(30-51)$ & $43 \pm 9(31-61)$ & 0.048 \\
PR fraction, \% & $17 \pm 13(0-45)$ & $3 \pm 3(0-7)$ & $<0.001$ \\
Peak systolic gradient, $\mathrm{mm} \mathrm{Hg}$ & $39 \pm 13(23-71)$ & $22 \pm 14(9-60)$ & 0.001 \\
\hline
\end{tabular}




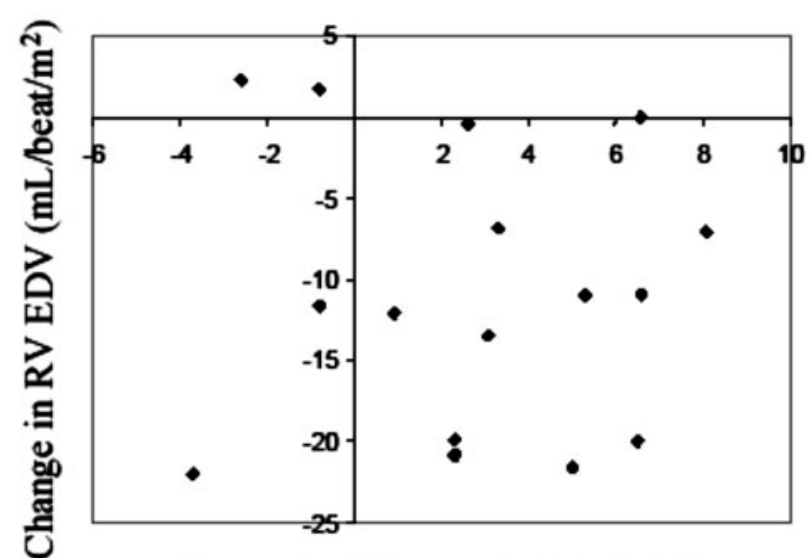

a)

\section{Change in $\mathrm{VO}_{2} \max (\mathrm{mL} / \mathrm{kg} / \mathrm{min})$}

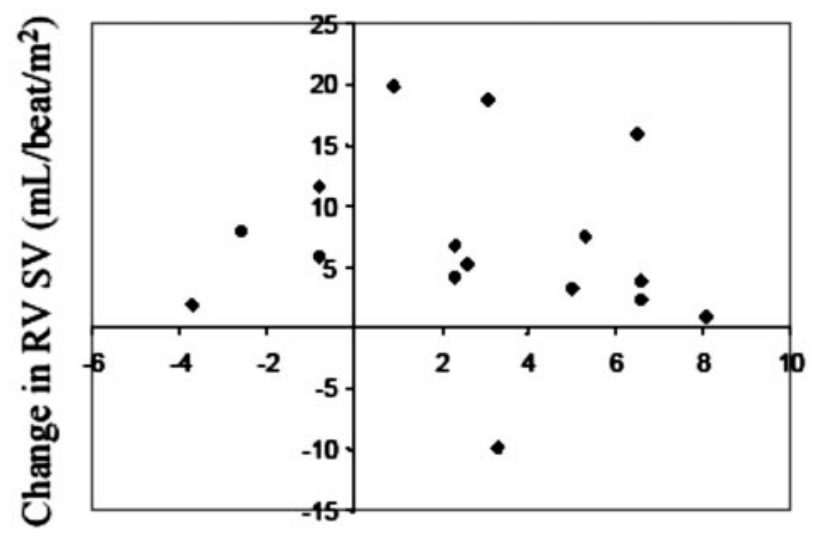

b)

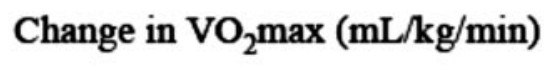

Figure 6. a, Plot of change in RVEDV against change in $\dot{\mathrm{V}}_{2}$ max. b, Plot of change in RVSV against change in $\dot{\mathrm{V}}_{2} \max$.

explant the device, and a valved conduit was successfully implanted, with good outcome. In the remaining patients who required explantation, a major indication was residual stenosis caused by either external compression of the conduit despite the presence of the stent or residual stenosis because of inability to deploy the device fully at implantation, 1 of them associated with intravascular hemolysis.

One patient developed endocarditis after a dental procedure without antibiotic prophylaxis and required explantation for failure of medical therapy.

The freedom from explantation for valve failure was $89 \%$ (95\% CI, $80 \%$ to $97 \%$ ) at 6 months, $83.3 \%$ (69.5\% to $97.2 \%)$ at 12 months, $79.7 \%(67.2 \%$ to $92.2 \%)$ at 24 months, and $69.8 \%(48.4 \%$ to $91.1 \%$ ) at 36 months (Figure 8$)$.

\section{Discussion}

Repair and reconstruction of RVOT has been undertaken with increasing success during corrective surgery for congenital heart disease; however, a significant number of patients have residual lesions. Pulmonary regurgitation is increasingly recognized as the major determinant of long-term morbidity and mortality in patients who had surgery on RVOT. ${ }^{13,17-20}$ RVOT dysfunction forms a major indication for reoperation

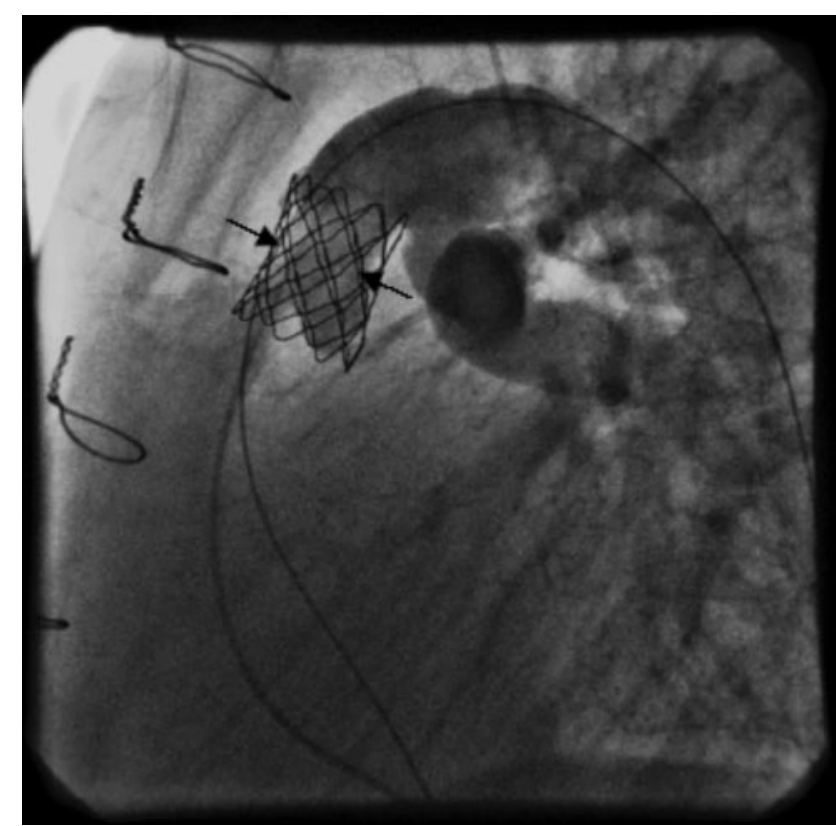

Figure 7. "Hammock" effect (arrows). The venous wall hanging in the stent causing stenosis.

in an adult congenital heart unit, and multiple operations are anticipated and performed. ${ }^{7}$

Stenosis has been accessible to interventional catheterization $^{21,22}$ with balloon dilatation and stent implantation with good early and mid-term relief of obstruction. This approach has been very effective in treating conduit stenosis not involving the valve leaflets. PPVI represents an important advance, because it deals successfully with both stenosis and regurgitation components of RVOT dysfunction. We have clearly shown a significant and sustained improvement in RV hypertension with relief of RVOT gradient in the subgroup of patients with predominant stenosis, with no significant regurgitation after PPVI. Furthermore, a significant and sustained improvement in pulmonary regurgitation was also achieved in the subgroup with predominant regurgitation.

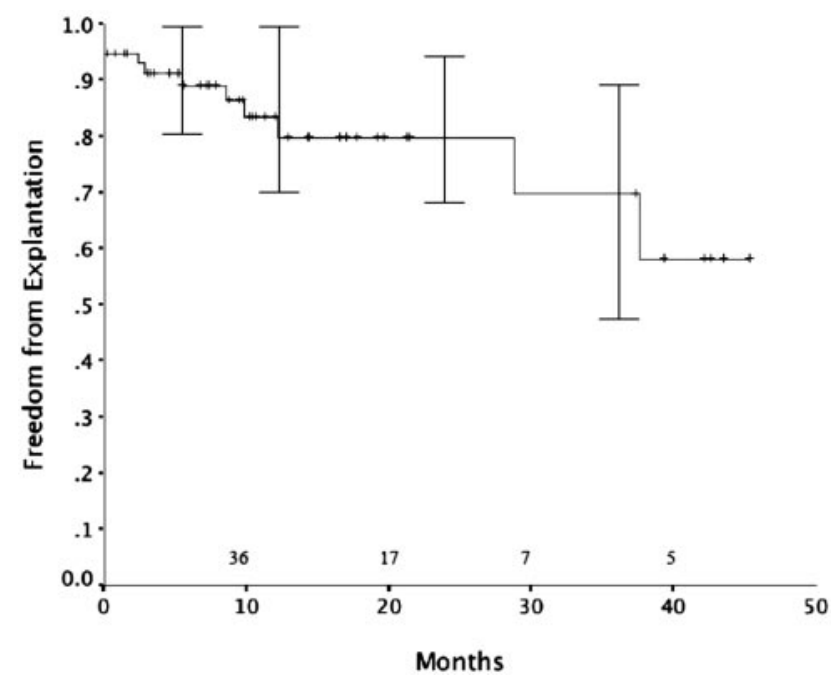

Figure 8. Kaplan-Meier plots for freedom from surgical explantation after transcatheter pulmonary valve implantation. Numbers on $x$ axis indicates patients at risk during follow-up. 
We observed 3 separate categories of complications. The first were complications related to balloon dilatation or stenting for conduit stenosis, including dissection, hemorrhage from conduit rupture, and residual stenosis because of external compression or undilatable conduits. ${ }^{21-23}$

The second category was related to issues of patient selection and occurred in the new substrate of patients with predominant regurgitation who have previously been accessible to interventional catheterization. Dislodgment or embolization of the valved stent during PPVI or follow-up occurred because of unfavorable shape, size, and elastic properties of the RVOT. Understanding wall characteristics and 3D dynamic imaging of RVOT would refine patient selection and is a key issue of current research by our group.

The third category, related to device design, included the "hammock" effect and stent fracture. The hammock effect was resolved during the series with an improved design, whereby the entire length of the stent was sutured to the venous wall segment. In one series, $16 \%$ of patients had stent fractures in RV to PA conduits. ${ }^{22}$ In our series, $12 \%$ of patients had stent fracture; however, only 2 had clinical consequences. One was treated with a second PPVI with a successful hemodynamic result. The other patient with stent embolism has been described in the earlier section.

Transcatheter pulmonary valve replacement provides a unique opportunity to study the response of the RV to acute pressure and volume unloading without the confounding effect of cardiopulmonary bypass. Previous studies after surgical pulmonary valve replacement have shown reduction in RVEDVs (MRI) ${ }^{12}$ and RV dimensions (echocardiography), ${ }^{11}$ and both improved subjectively ${ }^{11,12}$ and objectively (metabolic exercise testing), ${ }^{24}$ although no association between changes in ventricular parameters and exercise capacity has been shown.

Cardiovascular MRI assessment in patients with severe pulmonary regurgitation has demonstrated markedly elevated RVEDV and RVESV and reduced RVEF. ${ }^{25-28}$ This chronic $\mathrm{RV}$ volume overload has long been regarded as benign, but there is increasing evidence that RV function may be irreversibly compromised by such long-term changes. ${ }^{29}$ This is exemplified by 3 findings that have been demonstrated by cardiovascular MRI. First, RVEF has been shown to be significantly lower in patients with both RV pressure and volume overload compared with RV pressure overload alone. ${ }^{28}$ Second, an abnormal RV response to stress (either pharmacological ${ }^{28}$ or physiological ${ }^{30}$ ) has been demonstrated in patients with repaired tetralogy of Fallot and pulmonary regurgitation. And finally, there appears to be no significant improvement in RVEF at rest after pulmonary valve replacement. ${ }^{12,29}$

In our study, there was a reduction in RVEDV and improved performance at metabolic exercise testing (12 of 16 subjects), and in 2 subjects in whom RVEDV increased, there was reduced performance at metabolic exercise test (both predominant stenosis patients). The reduction in RVEDV was associated with an increase in LVEDV, which suggests that the mechanism of clinical improvement may be related to diastolic ventricular interaction. ${ }^{31}$ We propose that reduction in RVEDV after reduction in PR volume by valve implanta- tion permits an increase in LV filling and thus LVEDV. This occurs within the constraints of the pericardial space and, by the Frank-Starling mechanism, results in an increase in stroke volume, which may be responsible for the subjective and objective improvements in functional status. This mechanism is further supported by evidence in patients with heart failure, which suggests that abnormalities of LV diastolic function are a key determinant of exercise intolerance. ${ }^{32} \mathrm{~A}$ second explanation for the improved LV filling may simply be related to increased effective RVSV as a result of a reduction in RVOT obstruction, thus increasing pulmonary venous return, left atrial filling, and LV preload. Further studies are in progress to define the mechanism of ventricular interaction.

\section{Limitations}

Although we have demonstrated an immediate beneficial effect of PPVI, long-term follow-up will be essential to evaluate the potential for ventricular remodeling and sustained symptomatic relief. The subjects in this study were heterogeneous in terms of age, diagnosis, RVOT pathology, $\mathrm{RV}$ dilatation, and $\mathrm{RV}$ function.

As with all new procedures, whether surgical or interventional, we recognize the impact of learning curve on this novel technique. The reintervention and explantation rates may appear to be higher in direct comparison to surgical reports; however, evolution of device design and more experience have led to further a decrease, and indeed elimination, of some of the early problems. Also, our cohort of patients is complex, with a median of 3 operations on their RVOT before the PPVI. Despite this, and including the whole series right from the first case, there has been no mortality, either during the procedure or during late follow-up.

The patient population in our series had distinct RVOT dimensions and morphology favorable for implantation of the valved stent. We are working to expand this application to patients with dilated RVOTs with development of RVOT reducers. MRI and cardiopulmonary exercise testing could not be obtained in the entire cohort of patients.

\section{Summary}

Our PPVI program is the first clinical step in treatment of valvular regurgitation in the modern era of transcatheter therapeutics. This approach will alter strategies for transcatheter management of other heart valves and lead to a major change in the lifetime management of patients with congenital heart disease.

\section{Acknowledgments}

Dr Taylor was funded by the Higher Education Funding Council for England (HEFCE). Drs Coats, Boudjemline, Deanfield, and Bonhoeffer were funded by the British Heart Foundation. Drs Razavi, Muthurangu, and Hegde were funded by the HEFCE Joint Research Equipment Initiative; Philips Medical Systems, Best, the Netherlands; the Evelina Trust; and the Charitable Foundation of Guy's and St Thomas NHS Trust.

\section{Disclosure}

Dr Bonhoeffer is a consultant to Medtronic. 


\section{References}

1. Ross DN, Somerville J. Correction of pulmonary atresia with a homograft aortic valve. Lancet. 1966;2:1446-1447.

2. Rastelli GC, Wallace RB, Ongley PA. Complete repair of transposition of the great arteries with pulmonary stenosis: a review and report of a case corrected by using a new surgical technique. Circulation. 1969;39:83-95.

3. Bove EL, Lupinetti FM, Pridjian AK, Beekman RH III, Callow LB, Snider AR, Rosenthal A. Results of a policy of primary repair of truncus arteriosus in the neonate. J Thorac Cardiovasc Surg. 1993;105: 1057-1065.

4. Conte S, Jashari R, Eyskens B, Gewillig M, Dumoulin M, Daenen W. Homograft valve insertion for pulmonary regurgitation late after valveless repair of right ventricular outflow tract obstruction. Eur J Cardiothorac Surg. 1999;15:143-149.

5. Perron J, Moran AM, Gauvreau K, del Nido PJ, Mayer JE Jr, Jonas RA. Valved homograft conduit repair of the right heart in early infancy. Ann Thorac Surg. 1999;68:542-548.

6. Bando K, Danielson GK, Schaff HV, Mair DD, Julsrud PR, Puga FJ. Outcome of pulmonary and aortic homografts for right ventricular outflow tract reconstruction. J Thorac Cardiovasc Surg. 1995;109: 509-517.

7. Dore A, Glancy DL, Stone S, Menashe VD, Somerville J. Cardiac surgery for grown-up congenital heart patients: survey of 307 consecutive operations from 1991 to 1994. Am J Cardiol. 1997;80:906-913.

8. Bonhoeffer P, Boudjemline Y, Saliba Z, Merckx J, Aggoun Y, Bonnet D, Acar P, Le Bidois J, Sidi D, Kachaner J. Percutaneous replacement of pulmonary valve in a right-ventricle to pulmonary-artery prosthetic conduit with valve dysfunction. Lancet. 2000;356:1403-1405.

9. Bonhoeffer P, Boudjemline Y, Saliba Z, Hausse AO, Aggoun Y, Bonnet D, Sidi D, Kachaner J. Transcatheter implantation of a bovine valve in pulmonary position: a lamb study. Circulation. 2000;102:813-816.

10. Bonhoeffer P, Boudjemline Y, Qureshi SA, Le Bidois J, Iserin L, Acar P, Merckx J, Kachaner J, Sidi D. Percutaneous insertion of the pulmonary valve. J Am Coll Cardiol. 2002;39:1664-1669.

11. Warner KG, O’Brien PK, Rhodes J, Kaur A, Robinson DA, Payne DD. Expanding the indications for pulmonary valve replacement after repair of tetralogy of Fallot. Ann Thorac Surg. 2003;76:1066-1071.

12. Vliegen HW, van Straten A, de Roos A, Roest AA, Schoof PH, Zwinderman AH, Ottenkamp J, van der Wall EE, Hazekamp MG. Magnetic resonance imaging to assess the hemodynamic effects of pulmonary valve replacement in adults late after repair of tetralogy of Fallot. Circulation. 2002;106:1703-1707.

13. Bove EL, Kavey RE, Byrum CJ, Sondheimer HM, Blackman MS, Thomas FD. Improved right ventricular function following late pulmonary valve replacement for residual pulmonary insufficiency or stenosis. J Thorac Cardiovasc Surg. 1985;90:50-55.

14. Discigil B, Dearani JA, Puga FJ, Schaff HV, Hagler DJ, Warnes CA, Danielson GK. Late pulmonary valve replacement after repair of tetralogy of Fallot. J Thorac Cardiovasc Surg. 2001;121:344-351.

15. Bigras JL, Boutin C, McCrindle BW, Rebeyka IM. Short-term effect of monocuspid valves on pulmonary insufficiency and clinical outcome after surgical repair of tetralogy of Fallot. J Thorac Cardiovasc Surg. 1996; 112:33-37.

16. Taylor AM, Bogaert J. Imaging planes. In: Clinical Cardiac MRI. Bogaert J, Dymarkowski S, Taylor AM, eds. Heidelberg, Germany: Springer-Verlag; 2005;85-98.

17. Bove EL, Byrum CJ, Thomas FD, Kavey RE, Sondheimer HM, Blackman MS, Parker FB Jr. The influence of pulmonary insufficiency on ventricular function following repair of tetralogy of Fallot: evaluation using radionuclide ventriculography. J Thorac Cardiovasc Surg. 1983; 85:691-696
18. Therrien J, Siu SC, Harris L, Dore A, Niwa K, Janousek J, Williams WG, Webb G, Gatzoulis MA. Impact of pulmonary valve replacement on arrhythmia propensity late after repair of tetralogy of Fallot. Circulation. 2001;103:2489-2494.

19. Gatzoulis MA, Till JA, Redington AN. Depolarization-repolarization inhomogeneity after repair of tetralogy of Fallot: the substrate for malignant ventricular tachycardia? Circulation. 1997;95:401-404.

20. Gatzoulis MA, Balaji S, Webber SA, Webber SA, Siu SC, Hokanson JS, Poile C, Rosenthal M, Nakazawa M, Moller JH, Gillette PC, Webb GD, Redington AN. Risk factors for arrhythmia and sudden cardiac death late after repair of tetralogy of Fallot: a multicentre study. Lancet. 2000;356: 975-981.

21. Pedra CA, Justino H, Nykanen DG, VanArsdell G, Coles JG, Williams WG, Freedom RM, Benson LN. Percutaneous stent implantation to stenotic bioprosthetic valves in the pulmonary position. J Thorac Cardiovasc Surg. 2002;124:82-87.

22. Powell AJ, Lock JE, Keane JF, Perry SB. Prolongation of RV-PA conduit life span by percutaneous stent implantation: intermediate-term results. Circulation. 1995;92:3282-3288.

23. Ovaert C, Caldarone CA, McCrindle BW, Nykanen D, Freedom RM, Coles JG, Williams WG, Benson LN. Endovascular stent implantation for the management of postoperative right ventricular outflow tract obstruction: clinical efficacy. J Thorac Cardiovasc Surg. 1999;118: $886-893$.

24. Eyskens B, Reybrouck T, Bogaert J, Dymarkowsky S, Daenen W, Dumoulin M, Gewillig M. Homograft insertion for pulmonary regurgitation after repair of tetralogy of Fallot improves cardiorespiratory exercise performance. Am J Cardiol. 2000;85:221-225.

25. Helbing WA, Niezen RA, Le Cessie S, van der Geest RJ, Ottenkamp J, de Roos A. Right ventricular diastolic function in children with pulmonary regurgitation after repair of tetralogy of Fallot: volumetric evaluation by magnetic resonance velocity mapping. J Am Coll Cardiol. 1996;28: 1827-1835.

26. Singh GK, Greenberg SB, Yap YS, Delany DP, Keeton BR, Monro JL. Right ventricular function and exercise performance late after primary repair of tetralogy of Fallot with the transannular patch in infancy. Am J Cardiol. 1998;81:1378-1382.

27. Davlouros PA, Kilner PJ, Hornung TS, Li W, Francis JM, Moon JC, Smith GC, Tat T, Pennell DJ, Gatzoulis MA. Right ventricular function in adults with repaired tetralogy of Fallot assessed with cardiovascular magnetic resonance imaging: detrimental role of right ventricular outflow aneurysms or akinesia and adverse right-to-left ventricular interaction. J Am Coll Cardiol. 2002;40:2044-2052.

28. Tulevski II, Hirsch A, Dodge-Khatami A, Stoker J, van der Wall EE, Mulder BJ. Effect of pulmonary valve regurgitation on right ventricular function in patients with chronic right ventricular pressure overload. Am J Cardiol. 2003;92:113-116.

29. Therrien J, Siu SC, McLaughlin PR, Liu PP, Williams WG, Webb GD. Pulmonary valve replacement in adults late after repair of tetralogy of Fallot: are we operating too late? J Am Coll Cardiol. 2000;36:1670-1675.

30. Roest AA, Helbing WA, Kunz P, van den Aardweg JG, Lamb HJ, Vliegen HW, van der Wall EE, de Roos A. Exercise MR imaging in the assessment of pulmonary regurgitation and biventricular function in patients after tetralogy of Fallot repair. Radiology. 2002;223:204-211.

31. Atherton JJ, Moore TD, Lele SS, Thomson HL, Galbraith AJ, Belenkie I, Tyberg JV, Frenneaux M.P. Diastolic ventricular interaction in chronic heart failure. Lancet. 1997;349:720-724.

32. Parthenakis FI, Kanoupakis EM, Kochiadakis GE, Skalidis EI, Mezilis NE, Simantirakis EN, Kanakaraki MK, Vardas PE. Left ventricular diastolic filling pattern predicts cardiopulmonary determinants of functional capacity in patients with congestive heart failure. Am Heart J. 2000;140: $338-344$. 